\title{
Human in vitro models for understanding mechanisms of autism spectrum disorder
}

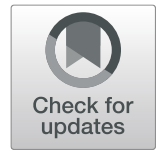

\author{
Aaron Gordon ${ }^{1}$ and Daniel H. Geschwind ${ }^{1,2,3,4^{*}}$
}

\begin{abstract}
Early brain development is a critical epoch for the development of autism spectrum disorder (ASD). In vivo animal models have, until recently, been the principal tool used to study early brain development and the changes occurring in neurodevelopmental disorders such as ASD. In vitro models of brain development represent a significant advance in the field. Here, we review the main methods available to study human brain development in vitro and the applications of these models for studying ASD and other psychiatric disorders. We discuss the main findings from stem cell models to date focusing on cell cycle and proliferation, cell death, cell differentiation and maturation, and neuronal signaling and synaptic stimuli. To be able to generalize the results from these studies, we propose a framework of experimental design and power considerations for using in vitro models to study ASD. These include both technical issues such as reproducibility and power analysis and conceptual issues such as the brain region and cell types being modeled.
\end{abstract}

\section{Early development as a critical period for ASD susceptibility}

Several emerging lines of evidence have established that disruption of prenatal brain development is a major risk pathway for development of autism spectrum disorder (ASD) [1-3]. Many of the genes found to be associated with ASD are highly co-expressed in both neural progenitors and newborn neurons and peak in expression during prenatal brain development [1-4]. Moreover, work integrating genome wide association study (GWAS) results [1] with gene regulatory interactions, including expression quantitative trait loci (eQTL) [5] and 3D chromatin structure, demonstrates enrichment of ASD risk alleles in human-specific gene enhancers active in fetal brain and, in particular, in neural progenitors [6].

\footnotetext{
* Correspondence: dhg@mednet.ucla.edu

'Department of Neurology, David Geffen School of Medicine, University of California Los Angeles, Los Angeles, CA, USA

${ }^{2}$ Program in Neurobehavioral Genetics, Semel Institute, David Geffen School of Medicine, University of California, Los Angeles, CA, USA

Full list of author information is available at the end of the article
}

At the neuropathological level, studies have identified abnormalities in cerebral cortex in individuals with ASD, including smaller neurons, a higher abundance of neurons, ectopic cells, and dendritic abnormalities, which are likely to be caused by abnormalities in cortical development [7]. Neuroimaging studies found changes in cortical surface area in ASD as early as 6 months postnatally, likely due to prenatal abnormalities in cortical development [8]. Another line of evidence comes from studies of environmental exposures associated with ASD. These include studies associating prenatal exposure to valproate [9], as well as to maternal bacterial [10] and viral infections during pregnancy (i.e., cytomegalovirus (CMV)) [11]. These diverse lines of evidence implicate early cortical development as one major convergent period of risk in the development of ASD. Even more remarkably, late onset disorders such as schizophrenia and bipolar disorder, as well as non-specific risk for neuropsychiatric disorders, have also been linked to fetal brain development-emphasizing the importance of development in susceptibility for psychiatric disorders more broadly [12-16]. 


\section{Animal models}

In vivo animal models are a major avenue of research for studying early brain development and how it is altered in ASD [17-21]. These models have many advantages as they can be used to study the entire process of brain development including age-dependent pathophysiology [21]. They allow for manipulation of specific genes on a homogeneous genetic background thus offering a way to study the effects of specific genes on the transcriptome, cell and circuit function, brain network activity, and behavior [17-21]. However, mouse models do not capture primate-specific or human-specific mechanisms active during early brain development or human complex genetic risk [22]. These human-specific mechanisms include many regulatory events, such as enhancer function and enhancer-promoter interactions, which govern gene expression in human neurogenesis and neurons [6, 13, 23-27].

Primate models are being developed to address some of these issues with mouse and other rodent models [28-30]. However, these primate models are expensive to develop and maintain, have a long reproductive cycle, and require careful ethical consideration [29]. Additionally, like mouse models, these models cannot yet capture genetic background effects or the polygenic contribution to ASD [31].

\section{In vitro options for studying human brain development}

In vitro models allow researchers to model typical early human brain development, as well as changes occurring in ASD and other neurodevelopmental disorders (NDDs) [32]. The advantages and disadvantages of the most widely used methods have been extensively reviewed [32-39] and are briefly summarized in Table 2. We provide an overview of the various major techniques below, which can broadly be categorized into three major groups based on the source of the cells used.

The first method utilizes primary human neural precursor cells (phNPCs) extracted from fetal postmortem cortex. These phNPCs are aggregated into neurospheres which can be cultured for extended periods of time [40]. These neurospheres are further differentiated into neurons and glia using combinations of growth factors [40, 41]. The resulting neurons closely model in vivo fetal cortical development up to mid-gestation (19-24 post conception weeks) [41]. The expression of a group (module) of genes harboring de novo loss of function mutations in ASD and related to chromatin remodeling in vivo was well preserved in phNPCs [41]. These results are consistent with data indicating that chromatin structure in these neurons, as queried by ATAC-seq, highly overlaps with in vivo patterns [12].
The second method, termed trans-differentiation, directly induces neurons (iNs) from non-neuronal cells by using combinations of induction factors which activate a neuronal transcription cascade [42, 43]. This method, which often uses combinations of transcription factors, can quickly generate many types of iNs from somatic cells and results in a mature post-mitotic population of iNs without going through a neural progenitor (NPC) stage $[42,43]$. These iNs retain many of the epigenetic marks of the source tissue [44, 45] which can capture the epigenetic signature of aging. This can be advantageous, for example, when studying neurodegenerative diseases [46, 47]. Given this method's speed and reliability of generating post mitotic maturing neurons, direct induction approaches can be advantageous, especially in the context of high throughput screens for which speed and reliability are paramount [42, 43, 48-55]. However, this method does not allow for complete and faithful modeling of fetal neuronal development, which depends on the correct sequence of developmental steps and epigenetic signature [44, 45, 56, 57].

The third method relies on embryonic (ESC) or induced pluripotent stem cells (iPSC) which are differentiated into heterogeneous cultures and can recapitulate different in vivo developmental stages [58]. One advantage of using iPSCs over ESC is that they can be generated from cells collected directly from individuals with ASD and can thus be used to capture both the genetic background, as it may influence major effect mutations, as well as idiopathic forms of ASD [32]. Another advantage is that the findings from iPSC derived from individuals with ASD can be integrated with available medical records, imaging results, and family pedigree which could supply the study with valuable phenotypic data. One example of this integrated head size as a phenotype to study changes occurring in individuals with ASD and macrocephaly $[59,60]$. These advantages are often also true for iNs derived from patients [39]; however, unlike iNs, iPSCs can recapitulate different in vivo developmental stages and have a methylation profile which resembles that of ESC [61-65]. It is important to note that iPSC do retain a small fraction of methylation markers from the donor, which can differ between different iterations of reprogramming and can depend on the source of the reprogrammed cells used [62, 63, 65]. Additionally, iPSCs tend to have lower genetic stability, sometimes leading to multiple unintended copy number variants $(\mathrm{CNV})$ and single nucleotide variants $(\mathrm{SNV})$, which necessitates whole genome sequencing to validate each line [66].

Both ES and iPSC can be differentiated into 2dimensional (2D) and 3-dimensional (3D) neuronal cultures. 2D cultures can be generated by adding growth factors $[67,68]$ or small molecules $[69,70]$ to the 
medium to generate NPC, which can then be further differentiated in neurons [39]. Direct differentiation into neurons which does not go through a NPC stage, as mentioned above, can also be achieved by overexpressing growth factors (e.g., NGN2, or Ascl1/Dlx2) [71, 72]. This can result in a more homogenous cell population and is highly scalable and reproducible [71, 72]. However, these mono-layer cultures do not fully capture in vivo brain development, as they lack the dense cellular environment of the brain which includes many synaptic and glial junctions [32, 39, 73]. Additionally, the direct to neuron methods may miss critical steps in the developmental trajectory of neurons where genetic risk may be acting, making them less suited to study neurodevelopment $[39,71]$.

3D cultures, also referred to as organoids, which capture more of the architecture (e.g., cortical layering) and cellular environment of in vivo brain development, can be organized by level of directed differentiation going from less directed to highly directed differentiation [32, 33, 38, 74-76]. While all differentiations are initially grown in neural induction media, in the less directed differentiations, the cells are not directed to differentiate into a specific brain region using additional factors [75, 77-80]. These differentiation methods lead to cultures with a variety of brain regions which can be used to study inter- and intra-regional connections [75, 81, 82]. However, these methods require careful assessment, particularly when studying disease, as regional heterogeneity can make these cultures extremely variable, making it difficult to compare between different cultures, even those that are presumed replicates from the same individual [81]. In contrast, the more directed differentiation protocols use specific combinations of morphogens, signaling molecules and growth factors to guide the cultures to differentiate into a specific brain region (often dorsal forebrain). To promote neural induction, many of these protocols initially add different combinations of growth factors (i.e., EGF, NT3, BDNF, and GDNF) [74, $78,79,83,84]$. This results in more reproducible cultures compared to the less directed differentiation, as seen by lower variability and more consistent cell types and cell proportions [74, 83-86]. More recently, multiple groups have described fusing the more directed organoids from different brain regions together. These combined cultures, termed assembloids, model the development of complex interconnected regions thus more faithfully recapitulating in vivo development and function [85, 87, 88]. For example, the fusing of dorsal and ventral forebrain cultures has been shown to reliably integrate interneurons into the dorsal forebrain [85, 87, 88].

Work in 3D in vitro models of brain development is in its early stages and more work is needed to improve their ability to faithfully and reproducibly recapitulate in vivo development. A recent study noted that these cultures can show increased levels of cell stress as well as reduced cell subtype specification compared to in vivo [78]. A noteworthy disadvantage of these 3D cultures compared to 2D cultures expressing NGN2 [71] and iNs $[42,43]$ is that while cells in these 2D methods take roughly 2 weeks ( 14 days) to differentiate into neurons, 3D cultures typically take 2-4 months (60-120 days) to reach differentiation levels similar to midgestation [74-76, 78, 83]. This makes the 3D cultures less scalable and therefore less suited for large scale screens [32, 33]. These longer differentiations, however, can also be viewed as an advantage, as they can lead to more mature cellular and transcriptomic phenotypes in both neurons and glia [77, 84, 89].

\section{Applications}

Studying neurodevelopmental and psychiatric disorders

In vitro models can be used to study the effects of both common and rare genetic variation on early human brain development at a cellular and molecular level, in both typical development and neurodevelopmental and psychiatric disorders. Since most genetic variation resides in non-coding regions, which are highly diverged between human and rodents [90], it is necessary to use primate or human models to understand the role of most regulatory variation [5], especially for ASD risk genes that are regulated by human evolved elements [6]. Moreover, studying the role of common genetic background on neurodevelopment in ASD and other psychiatric disorders is currently only feasible by studying patient-derived cellular models.

Using these models, one can compare differentiated cultures from individuals with ASD and other psychiatric disorders, either from those without a clearly defined genetic etiology or from those with genetically defined forms. This approach accounts for the genetic background and, in the case of genetically defined forms, also integrates the effects of the mutation with the genetic background, giving results that can reflect the complex genetic architecture of these disorders. A complementary approach to study genetically defined forms is to use isogenic lines in which researchers either induce mutations in control lines or correct mutations in lines derived from individuals with ASD, e.g., using CRISPR/Cas9 methods [91]. This approach minimizes variation caused by genetic background and directly links the observed phenotype with the mutation [91]. Thus, it allows for direct inference of the role that ASD risk genes play in neurodevelopment.

In addition to understanding both common and rare genetic risk, iPSC-derived models can also be used to study the role of environmental factors on both typical and atypical brain development. These environmental 
factors can be extrinsic, such as organophosphates [92] and bisphenol-A [93], or in utero factors such cortisol levels and inflammatory factors [94, 95]. For example, exposing neuroepithelial-like stem cells to high levels of glucocorticoids for $48 \mathrm{~h}$ transiently increased intracellular reactive oxygen species concentration [96]. This exposure led to persistent inhibition of neural differentiation and increase in glial differentiation [96].

\section{Precision medicine}

Stem cell models of brain development can also be used in the field of precision medicine [97]. Stem cell-derived neurons could serve as a potential diagnostic tool for enigmatic rare diseases. In cases where whole exome sequencing does not yield a diagnosis, transcriptomic analysis of relevant tissue has shown some promise [98101]. In cases when the relevant tissue is inaccessible (which is the majority of cases in neurodevelopmental and psychiatric disorders), blood transcriptomics sequencing has been suggested as an alternative and was shown to be informative in $7.5-16.7 \%$ of cases [101, 102]. However, many cases still remain undiagnosed, and it is reasonable to believe that transcriptomics sequencing from cells mimicking the relevant tissue by using stem cell-derived cultures would further increase this rate of diagnosis.

Additionally, given the high heterogeneity and polygenicity of psychiatric disorders, these in vitro models could help identify intermediate processes leading to neuronal dysfunction [103]. Combined with genetic data, medical record data, and imaging results, this could lead to stratification of patient populations into more homogenous cohorts and to development of cohortspecific treatments [97].

\section{Drug discovery}

Stem cell-based models can also be used to screen drugs for treatment of neurodevelopmental disorders including ASD [91, 104]. For example, one study screened 4421 unique compounds and identified 108 compounds that regulate neurite growth [105], a process which has been variably linked to some forms of ASD [106]. Another study screened a set of 50,000 compounds in neural stem cells to find activators of FMR1, a gene silenced in fragile X syndrome, which increases risk for ASD [107]. Similarly, a different study screened 202 compounds for their ability to restore SHANK3 expression in SHANK3 haplo-insufficient stem cell-derived neurons [108]. Two compounds, lithium and valproic acid (VPA), were found to restore SHANK3 expression and increase network connectivity in these neurons [108].

Additionally, stem cell-derived neurons from individuals with psychiatric disorders can be used for drug discovery and for tailoring drug regimens to specific individuals or subgroups. For example, reversal of hyperexcitability in iPSC-derived neurons from individuals with bipolar disorder was a good predictor for the responsiveness of these individuals to lithium therapeutics [109].

\section{Evolution of the human brain}

One other interesting emerging application is to study the evolution of the human brain by comparing cultures derived from human to other non-human primates which share many of the transcriptional programs determining cell type in the developing cerebellar cortex [82, $83,110,111]$. One study, using 2D and 3D stem cellderived cultures, found that differences in neuronal cell numbers among rodents, non-human primates, and humans could be partially explained by the differences in the presence and length of a developmental stage of cerebral cortex progenitor expansion that was significantly increased in humans [111]. Supporting this finding, two studies found that cellular maturation took longer in humans organoids compared to chimpanzee and bonobo organoids [82, 110]. Many upregulated genes and changes in DNA accessibility in these studies were identified as being specific to the developing human brain [82]. Additional support to the extended maturation of human cells comes from co-expression network analysis which identified human-specific transcriptional changes in groups of genes related to cell cycle and neuronal apoptosis [83].

\section{Main findings from stem cell models of ASD to date}

Two kinds of genetic modeling have been performed using cells either from individuals whose genetic contributions are unknown or undefined, so called idiopathic $[59,60,112-120]$, or from individuals harboring major effect mutations that are presumed causal or which have been engineered to carry these mutations. These mutations include ASD-associated CNVs such as 15q11q13 deletion (Angelman syndrome) [121] and duplication (Dup15q syndrome) [122], 22q11.2 deletion (DiGeorge syndrome) [123, 124], 16p11.2 deletion and duplication [125], and 15q13.3 deletion [126], as well as single-gene mutations including SHANK3 [127-130], CHD8 [131, 132], NRXN1 [133-137], NLGN4 [138], EHMT1 (Kleefstra syndrome) [139], PTCHD1-AS [140], UBE3A (Angelman's syndrome) [141], and CACNA1C (Timothy syndrome) [142] (summarized in Table 1). In this review, we will not discuss fragile X syndrome, Rett's syndrome, and tuberous sclerosis-related autism as they have all been extensively reviewed previously [148-154].

The majority of these studies used cells from patients, with some also including isogenic controls [121, 127, $131,134,145,146]$, while some studies exclusively used induced mutations comparing them with isogenic 


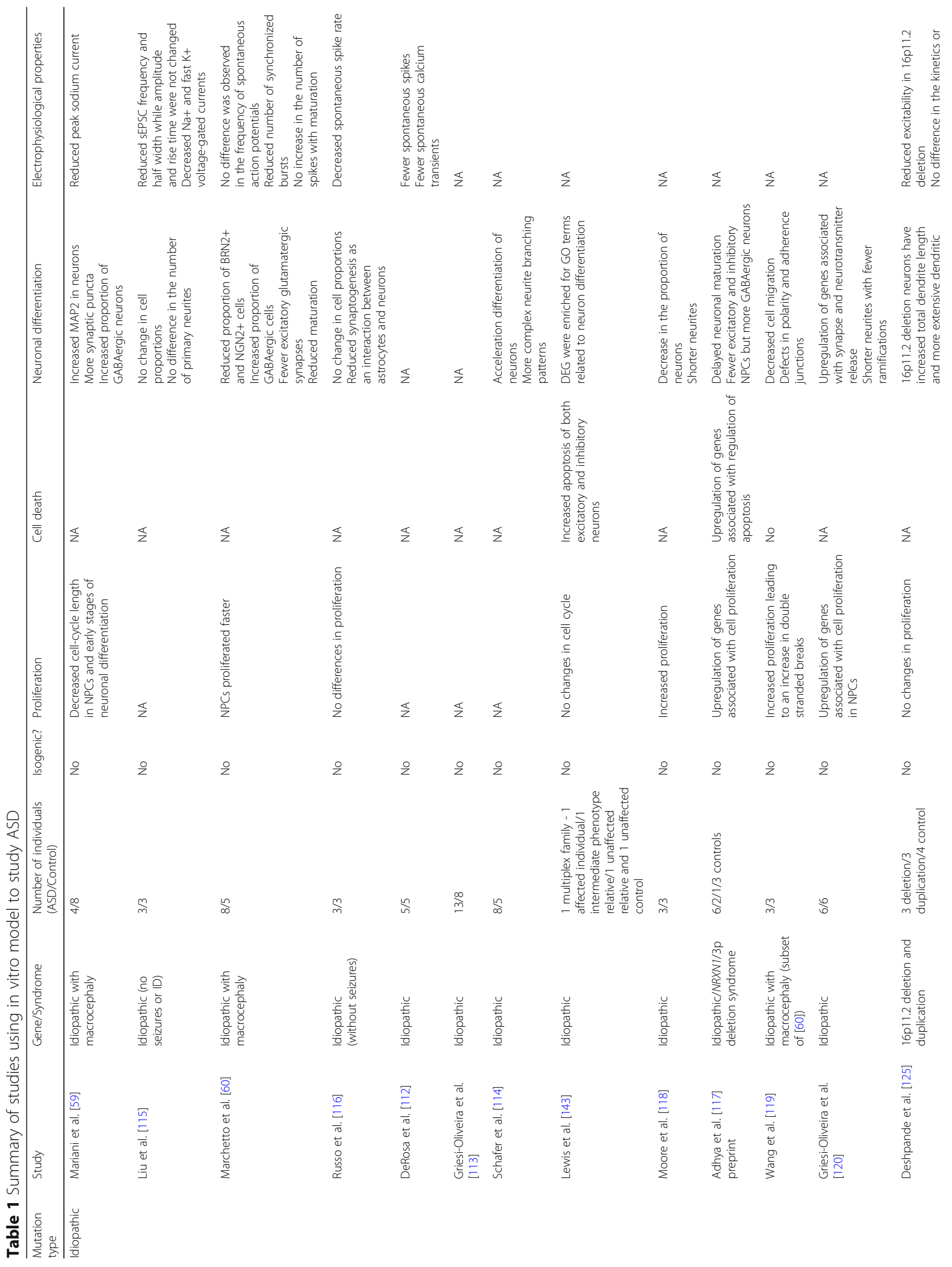




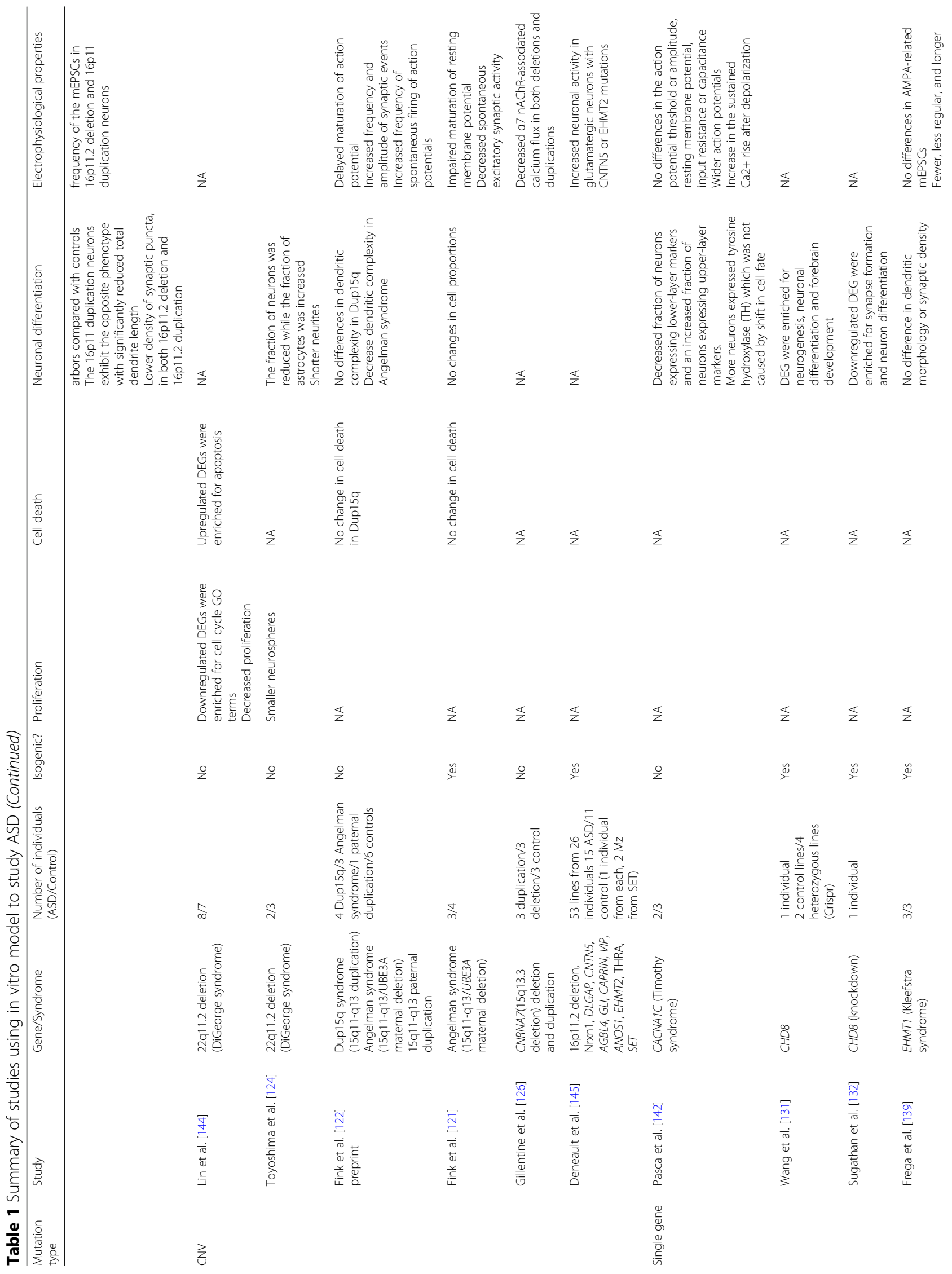




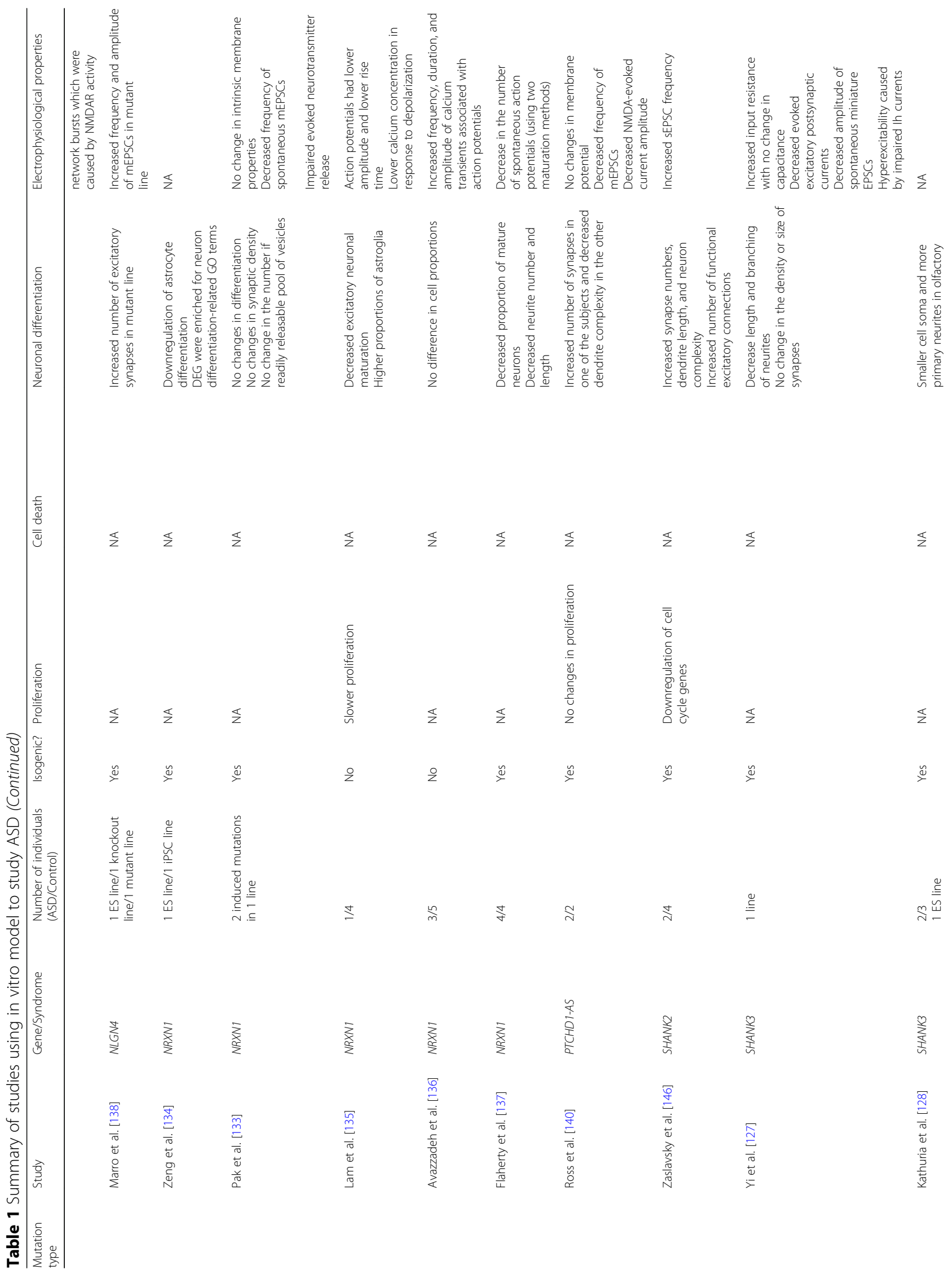




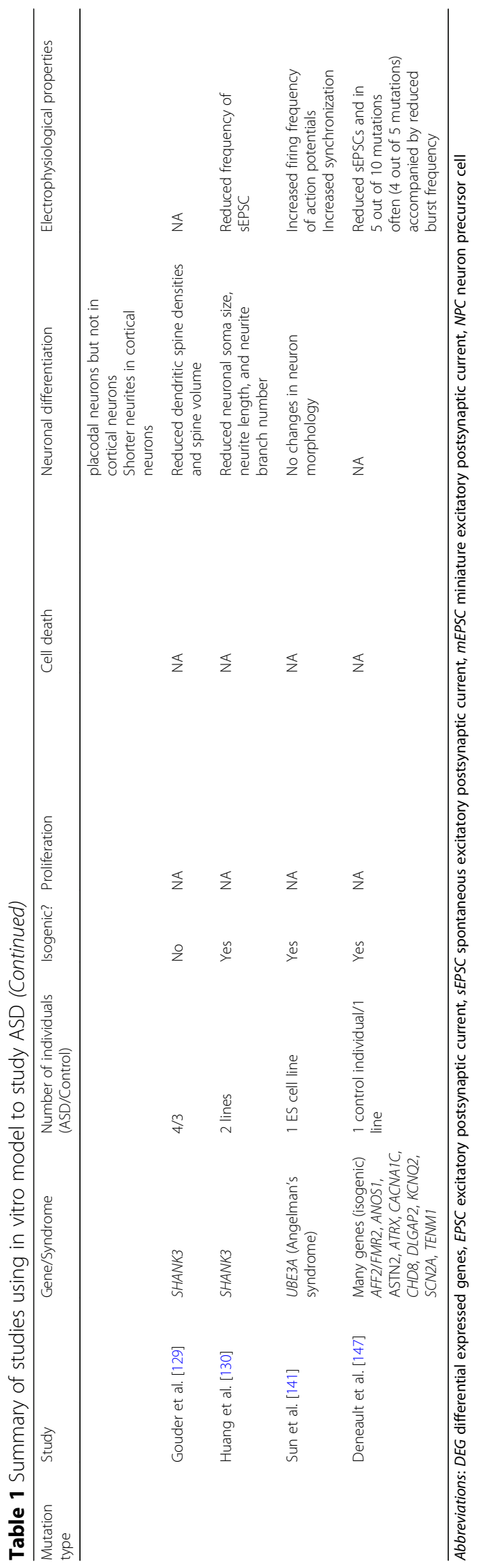


control lines [132, 133, 138, 141, 147] (Table 1). Many of the studies, from both idiopathic and genetically defined forms of ASD, found effects in one (or more) of four general categories of cellular biological processes: (1) cell cycle and proliferation, (2) cell death (specifically apoptosis), (3) cell differentiation and maturation, and (4) neuronal signaling and synaptic stimuli (Table 1). We have therefore organized the results according to these categories.

\section{Cell cycle and proliferation}

Several studies found changes in cell cycle in cells derived from both individuals with idiopathic or genetically defined forms of ASD. Neuronal cultures from individuals with idiopathic ASD and macrocephaly displayed accelerated cell cycle progression, accompanied by upregulation of genes involved in cell proliferation in several independent studies, making this one of the few findings to have been replicated [59, $60,117,119]$. Two studies also found that neurons derived from individuals with ASD but without macrocephaly also proliferated faster $[118,120]$. Conversely, genetically defined forms of ASD, mutation in NRXN1, and 22q11.2 deletion showed evidence of a decreased proliferation rate $[124,135$, 144]. However, it is important to note that not all studies that examined cell cycle found changes in ASD [116, 125, 140, 143].

The acceleration in cell cycle in idiopathic ASD supports a finding from toddlers with ASD in which cell cycle gene networks were positively correlated with brain volume [155]. This acceleration could explain the differences in neuronal number and brain growth across the life span of individuals with ASD [156], as well as the high prevalence of macrocephaly in individuals with ASD [157]. However, an important caveat to this finding is that these changes in cell cycle could be an artifact stemming from confounders within culturing conditions that are propagated due to small sample size. To address this, larger samples are needed with robust measures for the reproducibility of the culturing system.

\section{Cell death}

Studies in 22q11.2 deletion [144], as well as idiopathic forms of ASD [117, 143], found an increase in cell death-more specifically in apoptotic cell death-in mature neurons [117, 143, 144]. This increase in apoptotic cell death has also been described in vivo in a small sample of postmortem brains from children with idiopathic forms of ASD [158], a finding which has yet to be more broadly investigated.

\section{Neuronal differentiation and morphology}

Studies on neurons derived from individuals with idiopathic ASD show conflicting results relating to neuronal differentiation. One study performed on individuals with macrocephaly found a general increase in the number of neural precursor cells (NPCs) [60]. This increase was driven by an expanded proportion of GABAergic inhibitory precursors, which unexpectedly led to a reduced number of GABAergic neurons [60]. Compared to GABAergic inhibitory precursors, the proportion of glutamatergic precursors was reduced in these cultures and was accompanied by a decrease in the number of excitatory synapses [60]. The increase in the total number of neurons was replicated in another study using 3D cultures, which also found accelerated development in differentiating excitatory neurons and more complex neurite branching patterns [114].

However, not all studies have found the same changes in cell proportions. One study, also based on individuals with macrocephaly, found an increase in GABAergic cell number accompanied by an increased number of GABAergic synapses [59]. This study did not find any changes in the number of excitatory glutamatergic neurons and synapses [59]. More recently, this increase in GABAergic neurons but not glutamatergic neurons, has been partially replicated from non-macrocephalic individuals with ASD, finding an increase in GABAergic cell markers, but no long-term changes in glutamatergic cell markers [117]. Yet, another study found a decrease in the total number of neurons in cultures from individuals with ASD without macrocephaly [118]. Contrary to the studies above which found some changes in cell proportions, a study performed using iPSCs from individuals with idiopathic ASD [116] found no change in cell proportions, but rather observed a reduction in glutamatergic synaptogenesis. This reduction was attenuated by the astrocytes in the culture as it was only seen when both neurons and astrocytes were derived from the individuals with ASD but not when the astrocytes were derived from healthy individuals [116].

These often conflicting results likely arise from many factors, ranging from etiological diversity, to small sample sizes, to differences in the culturing conditions. Unless one controls for the extraordinary etiological/ genetic heterogeneity by studying known mutations, biological differences between a handful of different individuals with idiopathic ASD would likely swamp subtle differences in in vitro development, especially given the small effects sizes found in imaging studies [159]. The small sample sizes used in these studies (3-8 affected individuals per study) could also be a cause for these contradictory results. Small sample sizes have lower power to detect changes, tend to overestimate effect sizes, and can lead to low reproducibility [160]. Different 
culturing methods could also lead to very different results even when looking at the same individuals. This was demonstrated in one study, where the ASD phenotype of neurite complexity and length was completely dependent on the differentiation protocol [114]. When the neurons were generated via NPCs using extrinsic signals, an increase in neurites was observed, whereas when differentiating the cells directly into neurons by overexpressing NGN2, this phenotype could no longer be seen [114]. In another study that also highlighted the importance of culturing protocols, specifically the cell composition of these cultures, the source of the astrocytes co-cultured with neurons (control or ASD) had a large effect on the neuronal phenotype [116], demonstrating the importance of considering the extracellular environment and cell-cell communication in modeling development. To make the results from these studies more robust, one would ideally like to see larger, more well-powered studies and use of different culturing systems that best mirror in vivo development. Going beyond technical reproducibility, the contradictory findings in the literature emphasize that biological and genetic variability need to be better accounted for to be able to generalize the results. In summary, given the large heterogeneity and small effect sizes seen in these studies, combined with their relatively small sample sizes and variability in culturing methods, we find it difficult to generalize from any of the published findings based on studies of small numbers of patients with idiopathic ASD.

In contrast to the variable results in idiopathic ASD, findings from genetically defined forms of ASD are generally more coherent. This is consistent with the viewpoint that the phenotypic variability seen in the idiopathic forms of ASD is due, at least partially, to etiological diversity. Several genetic forms of ASD show a decrease in the number of neurons and synapses, including Timothy syndrome-in which there was a decrease in the fraction of neurons expressing lower layer markers [142] and 22q11.2 deletion, which showed a reduced number of neurons accompanied by an increase in the number of astrocytes [124]. Three studies on NRXN1 mutations also found evidence for a decrease in neuronal maturation [134, 135, 137], a finding which was not replicated in a different study [136]. Similar results (downregulation of neuronal processes) were indirectly observed using transcriptomic analysis from neurons in which CHD8 was either knocked down [132] or heterozygously deleted [131].

Neuronal morphology, and more specifically dendritic tree morphology, was also perturbed in many of the genetically defined forms of ASD. The size and complexity of the dendritic tree was decreased in neurons with SHANK3 [127-130]. One study also showed a reduction in spine density [129], though this result was not replicated by a different group [127]. Similar decreases in dendritic tree complexity were also found in neurons derived from individuals with Angelman syndrome [122] and in one individual with a PTCHD1-AS mutation [140]. However, not all genetic forms of ASD followed this pattern of decreased complexity of the dendritic tree. Notably, the 16p11.2 locus shows a dosage effect on the size and complexity of the dendritic tree [125]. The dendritic length was decreased in $16 \mathrm{p} 11.2$ deletion and was increased in 16p11.2 duplication [125]. Additionally, in contrast to the findings with SHANK3, SHANK2 loss of function mutations led to an increase in the number of synapses, as well as in the complexity of the dendritic tree [146]. Individuals with NLGN4 [138] and one individual with a PTCHD1-AS mutation [140] also showed an increase in the number of synapses.

Interestingly, similar to the findings in some of these stem cell models, gene sets related to neurons and synaptic activity are downregulated in the postmortem cortex of individuals with ASD [120, 161166] suggesting a possible point of convergence between some of the genetically defined and idiopathic forms of ASD.

\section{Neuronal signaling and synaptic function}

Dysregulation in neuronal differentiation and synaptic and dendritic deficits may underlie the decreased spontaneous activity and decreased excitability found in many studies. These are often observed in neurons derived from individuals with idiopathic forms of ASD [112, 116, 167], as well as from individuals with genetically defined forms of ASD such as SHANK3 [127, 130], 16p11.2 deletion and duplication [125], Angelman syndrome [121], Dup15q syndrome [122], NRXN1 mutations [133, 135, 137], and PTCHD1AS [140]. Decreases in spontaneous neuronal activity were also found in five out of ten genes associated with ASD when mutations were introduced into neurons derived from typically developing individuals (ATRX, AFF2, KCNQ2, SCN2A, and ASTN2; see Table 1 for the full list of genes tested) [147].

The evidence for decreased neuronal activity overlaps with findings from transcriptomic analysis of postmortem cortex from individuals without a clearly defined genetic etiology and individuals with Dup15q $[161,165,166]$. These analyses found downregulation of gene modules related to synaptic activity and neuronal firing $[161,165,166]$. Combining the postmortem results with results from the stem cell models suggests that these changes in neuronal properties start at early stages of development and may persist throughout development. Additionally, these findings could link the cellular and network phenotype seen in 
these cultures to the excitation-inhibition (E/I) imbalance which has been proposed as an organizing framework to understand network activity in ASD [168].

Collectively, these studies demonstrate the potential utility of using stem cell models to study ASD by capturing the changes in early brain developmental in ASD at cellular and molecular resolution, but reproducibility and variability remain challenges that each study needs to address. One important caveat is that as many of the individuals used in these studies have complex behavioral phenotypes and comorbidities (i.e., intellectual disability, macrocephaly, epilepsy etc.) and more work will be required to tease apart which of these phenotypes are directly related to the core symptoms of ASD and which may be related to other comorbidities.

\section{Experimental design and power considerations when using stem cell models to study ASD}

While in vitro systems allow us to directly model human brain development, they are only as good as their ability to reliably reproduce processes and cell types occurring in vivo. The first step is, therefore, to create culturing systems that are both scalable and reproducible [83, 84, 86, 169]. A recent study has taken a step in this direction by demonstrating that both scalability and reproducibility can be increased by using a xeno-free approach that simplifies the differentiation protocol by not re-plating cells or embedding them into extracellular matrices [86].

Next, as these in vitro models only approximate in vivo brain development, it is important to ascertain the maturity of the culture used in each study. One system to assess the maturity of the culture uses three different bioinformatic tools to compare the in vitro cultures to in vivo brain development based on their transcriptome [41]. These genome-wide measurements are an important unbiased complement to physiological and morphological analysis of maturation-related phenotypes.

Cell type composition can also have a profound effect on the results. For example, Russo et al. [116] found that the presence of astrocytes derived from iPSCs of individuals with ASD interacted with neurons derived from the same individual to decrease the number of excitatory synapses [116]. It is therefore important to fully characterize the cell types and proportions present in the culturing system either directly by using single-cell technologies such as single-cell RNA sequencing or flow cytometry or indirectly using immunodetection of cell markers. Another aspect highlighted by this study is the importance of having as complete a representation of cell types found in vivo as possible, as this can have a profound change on phenotype [116, 170, 171].
One more related aspect that needs to be considered is that of the brain region being modeled. Many brain regions are involved in different aspects of ASD [7, 172], each with its unique cellular composition and cytoarchitecture. It will therefore be essential to study the specific molecular and cellular changes in ASD in the different brain regions. As an example, one study derived both cortical and olfactory placodal neurons from the same individuals with SHANK3 mutations [128]. The olfactory placodal neurons had more branched neurite and smaller somas, whereas cortical neurons had shorter neurites [128]. To date, protocols exist for generating many brain regions including the cerebral cortex [74, 83, 169], ventral forebrain [85, 87, 88, 169], cerebellum [173], and midbrain [174]. There are also many protocols to generate specific cell types in 2D, including cortical projection [70], GABAergic neurons [72, 175], and hypothalamic neurons [176]. Combining the different protocols makes it possible to study the interaction between different brain regions [77, 177] and cell types $[178,179]$ and how these change in ASD. However, it is important to note the tension between the complexity of the system used and the system's throughput and reproducibility. Each factor and step used in a culture system comes with some intrinsic variability-meaning that the more factors and steps needed, the more variable the system becomes which can negatively impact reproducibility and throughput. This must be taken into account when designing experiments and will depend on the research questions.

Going beyond the ability of the cultures to reliably model brain development, it is also essential to ensure that the study is suitably powered. Studies to date have not provided a clear power analysis and the number of individuals tend to be relatively low, with most studies having 1-4 affected individuals with rare mutations and 3-8 individuals for studies of individuals with idiopathic forms of ASD (Table 1). A study exploring different experimental designs of disease modeling using iPSC suggests using at least 4 individuals with a known genetic lesion per group, with more individuals increasing the sensitivity of the study design [180]. The authors helpfully developed a framework (with an accompanying software packageiPSCpoweR) to assess the number of individuals needed per study [180]. These experimental design and power considerations are summarized in Fig. 1.

\section{Limitations and future directions of stem cell models for studying ASD}

Despite their strengths mentioned above and in Table 2, one has to recognize the limitations of these in vitro models, as is the case with any model system. One clear and obvious conceptual limitation is the lack of the 
ability to assess behavior. Another, more technical, limitation is the difficulty to collect and maintain large cohorts of iPSC lines, as is evident by the published studies' fairly small sample sizes (Table 1). This limitation makes it difficult to study the effects of common variation in ASD and limits the utility of these models for non-personalized drug and genetic screening. There are many efforts in the field to overcome this limitation by generating repositories of iPSC lines that will be available to researchers $[145,181-183]$. These large repositories will allow researchers to use larger sample sizes to study the effects of genetic background on ASD and will allow them to stratify their studies based on both symptoms and genetic background. Efforts are also being made to increase the throughput of these models to reduce variability and make them more amenable for drug and genetic screens $[84,86,184]$.

An additional limitation is that these models diverge from in vivo brain development in a number of aspects. Studies have shown that while human dorsal brain organoids contain cell types and histological structures that reflect in vivo cortex, they differ in their cell proportions and in the complexity of their structural organization $[74,76,83]$. Additionally, these brain organoids can show increased metabolic stress and reduced cell subtype specification $[78,83]$. That being said, these issues are surmountable, and further development of these models will need to account for these issues to bring the in vitro models closer to in vivo development. To evaluate the differences between in vitro models and in vivo brain development, single-cell and bulk transcriptomics can provide a quantitative roadmap for unbiased, sensitive comparisons between in vitro and in vivo development $[41,78,83,86]$. To improve the validity of these stem cell models, new protocols are being developed to generate organoids which include a more complete representation of the cell diversity found in vivo. Such methods include fusing dorsal and ventral forebrain organoids into so called assembloids, to incorporate inhibitory neurons $[85,87,88]$, adding growth factors and small molecules to organoid cultures to promote the genesis of oligodendrocytes $[185,186]$ and adding cells (e.g., microglia) grown separately in 2D [187189]. Scaffolds are also being developed to increase the structural accuracy of these models [190], a direction which has shown success in modeling other tissues [191, 192].

Another limitation, especially for 3D cultures, is the extended period of time it takes to generate these cultures $[77,81]$. For example, one study has shown that to achieve later stages of maturation, including astrocyte maturation, 3D cultures had to be maintained for 9 months [77]. This challenges the feasibility of using these 3D cultures on a very large scale and considerably slows down experimental turnover. One alternative is to use 2D differentiations for these assays, as they have a faster maturation rate $[42,43,70,71]$. However, as mentioned earlier, these methods diverge significantly from in vivo brain development. Research is, therefore, needed to explore the possibility of accelerating the maturation of the 3D models [193]. One possible way of addressing this limitation is by increasing the oxygen accessibility of the models. A recent study showed that increasing

\section{Framework of experimental design for culturing stem cell models}

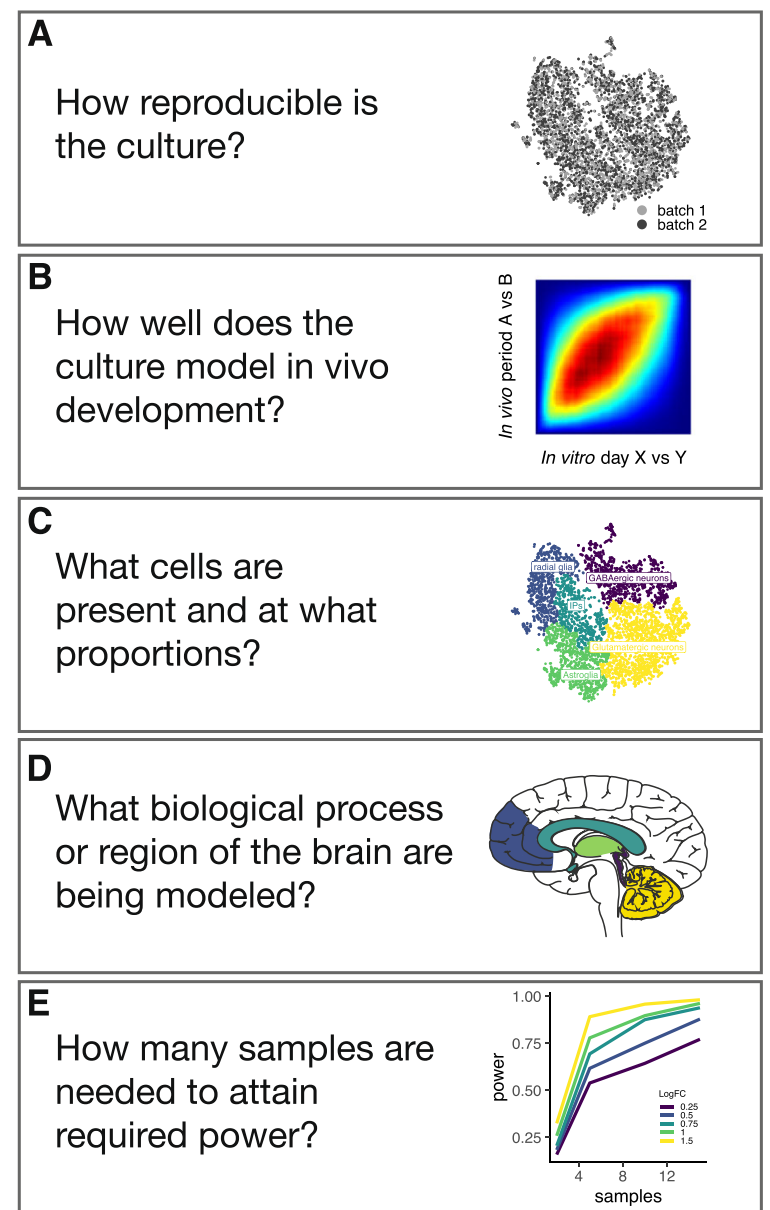

Fig. 1 A framework of experimental design and power considerations for culturing stem cell models. a Reproducibility can be determined by cell counts, immunocytochemistry, and more recently, single-cell and bulk sequencing. $\mathbf{b}$ Accuracy of the model can be determined by immunocytochemistry, by single-cell sequencing, and by using tools such as Transition Mapping [41]. c Cell proportion can be determined by single-cell sequencing, immunocytochemistry, and flow cytometry. d Biological process and region of the brain being modeled can be determined by identifying cell populations using single-cell sequencing and immunocytochemistry as well as by using Transition Mapping [41]. e Power can be determined using dedicated tools such as iPSCpoweR [180]. Image of brain adapted from Servier Medical art by Servier under Creative Commons License 3.0 (smart.senvier.com) 


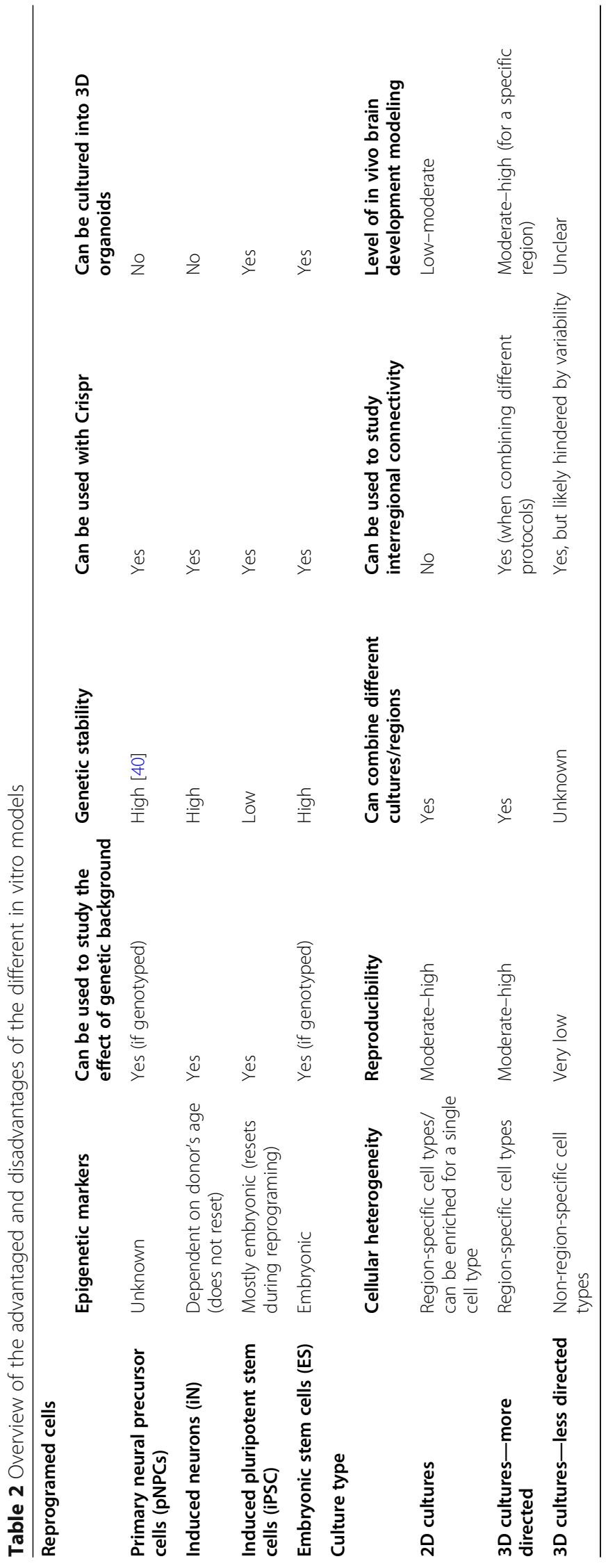


oxygen accessibility to organoids increases their maturation and structural complexity [177]. However, this method is labor intensive and is not representative of the processes in vivo. A more physiologically relevant method would be to incorporate vasculature and a functional blood brain barrier [194] which would allow for oxygen and nutrients to permeate the entire organoid. An analogous method is to transplant the organoids into a host organism such as mice or rats. This method, while having a low throughput, allowed the organoids to progressively mature and form intact networks between the organoid and the host [78, 195, 196].

\section{Conclusion}

The promise of stem cell models to study both typical and non-typical human brain development is already coming to fruition. However, careful consideration is needed when designing experiments using these models by taking into account both biological, (i.e., maturity and cell composition) and technical considerations (number of samples, protocol variability, differentiation time) for these models to meet their full potential.

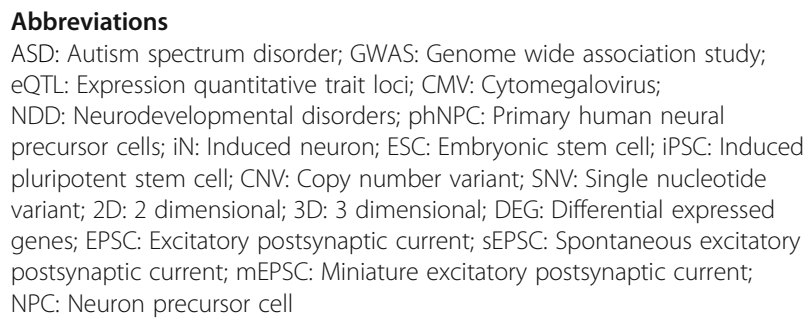

\section{Acknowledgements}

The authors would like to thank George Chen and Luis de la Torre-Ubieta for helpful discussions and critical reading of the manuscript

\section{Authors' contributions}

AG and DHG wrote the manuscript. All authors read, corrected, and approved the final manuscript.

\section{Funding}

This work was supported by the Autism Science Foundation (to AG), the Brain and Behavior Research Foundation Young Investigator award (Brain \& Behavior Research Foundation) (to AG), the California Institute of Regenerative Medicine (CIRM) (to DHG), and the National Institute of Mental Health (NIMH) (5U01MH115746, 1U01MH116489) (to DHG).

\section{Availability of data and materials}

Not applicable

\section{Ethics approval and consent to participate}

Not applicable

\section{Consent for publication}

Not applicable

\section{Competing interests}

DHG serves as a scientific advisor for Ovid Therapeutics, which is developing therapeutics for rare neurodevelopmental disorders.

\section{Author details}

'Department of Neurology, David Geffen School of Medicine, University of California Los Angeles, Los Angeles, CA, USA. ${ }^{2}$ Program in Neurobehavioral Genetics, Semel Institute, David Geffen School of Medicine, University of California, Los Angeles, CA, USA. ${ }^{3}$ Center for Autism Research and Treatment, Semel Institute, David Geffen School of Medicine, University of California, Los Angeles, CA, USA. ${ }^{4}$ Department of Human Genetics, David Geffen School of Medicine, University of California, Los Angeles, CA, USA.

Received: 23 December 2019 Accepted: 1 April 2020

Published online: 16 April 2020

\section{References}

1. Grove J, Ripke S, Als TD, Mattheisen M, Walters RK, Won H, et al. Identification of common genetic risk variants for autism spectrum disorder. Nat Genet. 2019;51(3):431-44.

2. Parikshak NN, Luo R, Zhang A, Won H, Lowe JK, Chandran V, et al. Integrative functional genomic analyses implicate specific molecular pathways and circuits in autism. Cell. 2013;155(5):1008-21.

3. Willsey AJ, Sanders SJ, Li M, Dong S, Tebbenkamp AT, Muhle RA, et al. Coexpression networks implicate human midfetal deep cortical projection neurons in the pathogenesis of autism. Cell. 2013;155(5):997-1007.

4. Ben-David E, Shifman S. Combined analysis of exome sequencing points toward a major role for transcription regulation during brain development in autism. Mol Psychiatry. 2013;18(10):1054-6.

5. Walker RL, Ramaswami G, Hartl C, Mancuso N, Gandal MJ, de la Torre-Ubieta $L$, et al. Genetic control of expression and splicing in developing human brain informs disease mechanisms. Cell. 2019;179(3):750-71.e22.

6. Won H, Huang J, Opland CK, Hartl CL, Geschwind DH. Human evolved regulatory elements modulate genes involved in cortical expansion and neurodevelopmental disease susceptibility. Nat Commun. 2019;10(1):2396.

7. Chen JA, Peñagarikano O, Belgard TG, Swarup V, Geschwind DH. The emerging picture of autism spectrum disorder: genetics and pathology. Annu Rev Pathol. 2015;10(1):111-44.

8. Hazlett HC, Gu H, Munsell BC, Kim SH, Styner M, Wolff JJ, et al. Early brain development in infants at high risk for autism spectrum disorder. Nature. 2017:542(7641):348-51.

9. Christensen J, Grønborg TK, Sørensen MJ, Schendel D, Parner ET, Pedersen $\mathrm{LH}$, et al. Prenatal valproate exposure and risk of autism spectrum disorders and childhood autism. JAMA. 2013;309(16):1696-703.

10. Croen LA, Qian Y, Ashwood P, Zerbo O, Schendel D, Pinto-Martin J, et al. Infection and fever in pregnancy and autism spectrum disorders: findings from the study to explore early development. Autism Res. 2019;12(10):1551-61.

11. Slawinski BL, Talge N, Ingersoll B, Smith A, Glazier A, Kerver J, et al. Maternal cytomegalovirus sero-positivity and autism symptoms in children. Am J Reprod Immunol. 2018;79(5):e12840.

12. de la Torre-Ubieta L, Stein JL, Won H, Opland CK, Liang D, Lu D, et al. The Dynamic landscape of open chromatin during human cortical neurogenesis. Cell. 2018;172(1-2):289-304 e18.

13. Won H, de la Torre-Ubieta L, Stein JL, Parikshak NN, Huang J, Opland CK, et al. Chromosome conformation elucidates regulatory relationships in developing human brain. Nature. 2016;538(7626):523-7.

14. Birnbaum $R$, Weinberger DR. Genetic insights into the neurodevelopmental origins of schizophrenia. Nat Rev Neurosci. 2017;18(12):727-40.

15. Clifton NE, Hannon E, Harwood JC, Florio AD, Thomas KL, Holmans PA, et al. Dynamic expression of genes associated with schizophrenia and bipolar disorder across development. Translat Psychiatry. 2019:9(1):1-9.

16. Schork AJ, Won H, Appadurai V, Nudel R, Gandal M, Delaneau O, et al. A genome-wide association study of shared risk across psychiatric disorders implicates gene regulation during fetal neurodevelopment. Nat Neurosci. 2019:22(3):353-61.

17. Qiu S, Aldinger KA, Levitt P. Modeling of autism genetic variations in mice: focusing on synaptic and microcircuit dysfunctions. Dev Neurosci. 2012; 34(2-3):88-100,

18. Provenzano G, Zunino G, Genovesi S, Sgado P, Bozzi Y. Mutant mouse models of autism spectrum disorders. Dis Markers. 2012;33(5):225-39.

19. Ellegood J, Crawley JN. Behavioral and neuroanatomical phenotypes in mouse models of autism. Neurotherapeutics. 2015;12(3):521-33. 
20. de la Torre-Ubieta L, Won H, Stein JL, Geschwind DH. Advancing the understanding of autism disease mechanisms through genetics. Nat Med. 2016;22(4):345-61.

21. Monteggia LM, Heimer H, Nestler EJ. Meeting report: can we make animal models of human mental illness? Biol Psychiatry. 2018.

22. Geschwind Daniel H, Rakic P. Cortical evolution: judge the brain by its cover. Neuron. 2013;80(3):633-47.

23. Hawrylycz M, Miller JA, Menon V, Feng D, Dolbeare T, Guillozet-Bongaarts $\mathrm{AL}$, et al. Canonical genetic signatures of the adult human brain. Nat Neurosci. 2015;18(12):1832-44.

24. Hodge RD, Bakken TE, Miller JA, Smith KA, Barkan ER, Graybuck LT, et al. Conserved cell types with divergent features in human versus mouse cortex. Nature. 2019

25. Khaitovich P, Muetzel B, She X, Lachmann M, Hellmann I, Dietzsch J, et al. Regional patterns of gene expression in human and chimpanzee brains. Genome Res. 2004;14(8):1462-73.

26. Hardingham GE, Pruunsild P, Greenberg ME, Bading $H$. Lineage divergence of activity-driven transcription and evolution of cognitive ability. Nat Rev Neurosci. 2018;19(1):9-15.

27. Doan RN, Bae BI, Cubelos B, Chang C, Hossain AA, Al-Saad S, et al. Mutations in human accelerated regions disrupt cognition and social behavior. Cell. 2016;167(2):341-54 e12.

28. Bauman MD, Schumann CM. Advances in nonhuman primate models of autism: integrating neuroscience and behavior. Exp Neurol. 2018;299(Pt A): 252-65.

29. Zhao $H$, Jiang $Y H$, Zhang $Y Q$. Modeling autism in non-human primates: opportunities and challenges. Autism Res. 2018;11(5):686-94.

30. Zhou Y, Sharma J, Ke Q, Landman R, Yuan J, Chen H, et al. Atypical behaviour and connectivity in SHANK3-mutant macaques. Nature. 2019; 570(7761):326-31.

31. Varghese M, Keshav N, Jacot-Descombes S, Warda T, Wicinski B, Dickstein $\mathrm{DL}$, et al. Autism spectrum disorder: neuropathology and animal models. Acta Neuropathol. 2017;134(4):537-66.

32. Amin ND, Paşca SP. Building models of brain disorders with threedimensional organoids. Neuron. 2018;100(2):389-405

33. Di Lullo E, Kriegstein AR. The use of brain organoids to investigate neural development and disease. Nat Rev Neurosci. 2017;18(10):573-84.

34. Pasca SP. The rise of three-dimensional human brain cultures. Nature. 2018; 553(7689):437-45.

35. Mertens J, Reid D, Lau S, Kim Y, Gage FH. Aging in a Dish: iPSC-derived and directly induced neurons for studying brain aging and age-related neurodegenerative diseases. Annu Rev Genet. 2018;52(1):271-93.

36. Brown J, Quadrato G, Arlotta P. Chapter Four - Studying the brain in a dish: 3D cell culture models of human brain development and disease. In: Brivanlou AH, editor. Current Topics in Developmental Biology. Human Embryonic Stem Cells in Development: 129: Academic Press; 2018. p. 99-122.

37. Centeno EGZ, Cimarosti H, Bithell A. 2D versus $3 D$ human induced pluripotent stem cell-derived cultures for neurodegenerative disease modelling. Mol Neurodegener. 2018;13.

38. Setia H, Muotri AR. Brain organoids as a model system for human neurodevelopment and disease. Semin Cell Dev Biol. 2019.

39. Mertens J, Marchetto MC, Bardy C, Gage FH. Evaluating cell reprogramming, differentiation and conversion technologies in neuroscience. Nat Rev Neurosci. 2016;17(7):424-37.

40. Svendsen CN, ter Borg MG, Armstrong RJ, Rosser AE, Chandran S, Ostenfeld $T$, et al. A new method for the rapid and long term growth of human neural precursor cells. J Neurosci Methods. 1998;85(2):141-52.

41. Stein JL, de la Torre-Ubieta L, Tian Y, Parikshak NN, Hernandez IA, Marchetto $M C$, et al. A quantitative framework to evaluate modeling of cortical development by neural stem cells. Neuron. 2014;83(1):69-86.

42. Vierbuchen $T$, Ostermeier A, Pang ZP, Kokubu Y, Südhof TC, Wernig M Direct conversion of fibroblasts to functional neurons by defined factors. Nature. 2010:463(7284):1035-41.

43. Tsunemoto R, Lee S, Szücs A, Chubukov P, Sokolova I, Blanchard JW, et al. Diverse reprogramming codes for neuronal identity. Nature. 2018;557(7705):375-80.

44. Mertens J, Paquola ACM, Ku M, Hatch E, Böhnke L, Ladjevardi S, et al. Directly reprogrammed human neurons retain aging-associated transcriptomic signatures and reveal age-related nucleocytoplasmic defects. Cell Stem Cell. 2015;17(6):705-18.
45. Huh CJ, Zhang B, Victor MB, Dahiya S, Batista LF, Horvath S, et al. Maintenance of age in human neurons generated by microRNA-based neuronal conversion of fibroblasts. Elife. 2016;5.

46. Horvath S. DNA methylation age of human tissues and cell types. Genome Biol. 2013;14(10):R115

47. Hannum G, Guinney J, Zhao L, Zhang L, Hughes G, Sadda S, et al. Genomewide methylation profiles reveal quantitative views of human aging rates. Mol Cell. 2013;49(2):359-67.

48. Ambasudhan R, Talantova M, Coleman R, Yuan X, Zhu S, Lipton SA, et al. Direct reprogramming of adult human fibroblasts to functional neurons under defined conditions. Cell Stem Cell. 2011;9(2):113-8.

49. Pang ZP, Yang N, Vierbuchen T, Ostermeier A, Fuentes DR, Yang TQ, et al. Induction of human neuronal cells by defined transcription factors. Nature. 2011;476(7359):220-3.

50. Yoo AS, Sun AX, Li L, Shcheglovitov A, Portmann T, Li Y, et al. MicroRNAmediated conversion of human fibroblasts to neurons. Nature. 2011; 476(7359):228-31

51. Ladewig J, Mertens J, Kesavan J, Doerr J, Poppe D, Glaue F, et al. Small molecules enable highly efficient neuronal conversion of human fibroblasts. Nat Methods. 2012;9(6):575-8.

52. Xue $Y$, Ouyang $K$, Huang J, Zhou Y, Ouyang H, Li H, et al. Direct conversion of fibroblasts to neurons by reprogramming PTB-regulated microRNA circuits. Cell. 2013;152(1-2):82-96.

53. Lau S, Rylander Ottosson D, Jakobsson J, Parmar M. Direct neural conversion from human fibroblasts using self-regulating and nonintegrating viral vectors. Cell Rep. 2014;9(5):1673-80.

54. Hu W, Qiu B, Guan W, Wang Q, Wang M, Li W, et al. Direct conversion of normal and Alzheimer's disease human fibroblasts into neuronal cells by small molecules. Cell Stem Cell. 2015;17(2):204-12.

55. Li X, Zuo X, Jing J, Ma Y, Wang J, Liu D, et al. Small-molecule-driven direct reprogramming of mouse fibroblasts into functional neurons. Cell Stem Cell. 2015;17(2):195-203.

56. Lee SH, Jeyapalan JN, Appleby V, Mohamed Noor DA, Sottile V, Scotting PJ. Dynamic methylation and expression of Oct4 in early neural stem cells. J Anat. 2010;217(3):203-13.

57. Watanabe D, Uchiyama K, Hanaoka K. Transition of mouse de novo methyltransferases expression from Dnmt3b to Dnmt3a during neural progenitor cell development. Neuroscience. 2006;142(3):727-37.

58. Takahashi K, Tanabe K, Ohnuki M, Narita M, Ichisaka T, Tomoda K, et al. Induction of pluripotent stem cells from adult human fibroblasts by defined factors. Cell. 2007;131(5):861-72.

59. Mariani J, Coppola G, Zhang P, Abyzov A, Provini L, Tomasini L, et al. FOXG1-dependent dysregulation of GABA/glutamate neuron differentiation in autism spectrum disorders. Cell. 2015;162(2):375-90.

60. Marchetto MC, Belinson H, Tian Y, Freitas BC, Fu C, Vadodaria K, et al. Altered proliferation and networks in neural cells derived from idiopathic autistic individuals. Mol Psychiatry. 2017;22(6):820-35.

61. de Boni L, Gasparoni G, Haubenreich C, Tierling S, Schmitt I, Peitz M, et al. DNA methylation alterations in IPSC- and hESC-derived neurons: potential implications for neurological disease modeling. Clin Epigenetics. 2018;10:13.

62. Kim K, Doi A, Wen B, Ng K, Zhao R, Cahan P, et al. Epigenetic memory in induced pluripotent stem cells. Nature. 2010;467(7313):285-sss90.

63. Bar S, Benvenisty N. Epigenetic aberrations in human pluripotent stem cells. EMBO J. 2019;38(12)

64. Tesarova L, Simara P, Stejskal S, Koutna I. The aberrant DNA methylation profile of human induced pluripotent stem cells is connected to the reprogramming process and is normalized during in vitro culture. PLOS One. 2016;11(6):e0157974.

65. Roost MS, Slieker RC, Bialecka M, van Iperen L, Gomes Fernandes MM, He N, et al. DNA methylation and transcriptional trajectories during human development and reprogramming of isogenic pluripotent stem cells. Nat Commun. 2017:8(1):908.

66. Popp B, Krumbiegel M, Grosch J, Sommer A, Uebe S, Kohl Z, et al. Need for high-resolution genetic analysis in iPSC: results and lessons from the ForIPS consortium. Sci Rep. 2018;8(1):1-14.

67. Zhang SC, Wernig M, Duncan ID, Brustle O, Thomson JA. In vitro differentiation of transplantable neural precursors from human embryonic stem cells. Nat Biotechnol. 2001;19(12):1129-33.

68. Yan Y, Yang D, Zarnowska ED, Du Z, Werbel B, Valliere C, et al. Directed differentiation of dopaminergic neuronal subtypes from human embryonic stem cells. Stem Cells. 2005;23(6):781-90. 
69. Chambers SM, Fasano CA, Papapetrou EP, Tomishima M, Sadelain M, Studer L. Highly efficient neural conversion of human ES and iPS cells by dual inhibition of SMAD signaling. Nat Biotechnol. 2009;27(3):275-80.

70. Shi Y, Kirwan P, Livesey FJ. Directed differentiation of human pluripotent stem cells to cerebral cortex neurons and neural networks. Nat Prot. 2012; 7(10):1836-46.

71. Zhang Y, Pak C, Han Y, Ahlenius H, Zhang Z, Chanda S, et al. Rapid singlestep induction of functional neurons from human pluripotent stem cells. Neuron. 2013;78(5):785-98.

72. Yang N, Chanda S, Marro S, Ng Y-H, Janas JA, Haag D, et al. Generation of pure GABAergic neurons by transcription factor programming. Nature Methods. 2017;14(6):621-8

73. Lee CT, Bendriem RM, Wu WW, Shen RF. 3D brain Organoids derived from pluripotent stem cells: promising experimental models for brain development and neurodegenerative disorders. J Biomed Sci. 2017;24(1):59.

74. Pasca AM, Sloan SA, Clarke LE, Tian Y, Makinson CD, Huber N, et al. Functional cortical neurons and astrocytes from human pluripotent stem cells in 3D culture. Nat Methods. 2015;12(7):671-8.

75. Lancaster MA, Renner M, Martin CA, Wenzel D, Bicknell LS, Hurles ME, et al Cerebral organoids model human brain development and microcephaly. Nature. 2013;501(7467):373-9.

76. Qian X, Nguyen HN, Song MM, Hadiono C, Ogden SC, Hammack C, et al. Brain-region-specific organoids using mini-bioreactors for modeling ZIKV exposure. Cell. 2016;165(5):1238-54.

77. Sloan SA, Darmanis S, Huber N, Khan TA, Birey F, Caneda C, et al. Human Astrocyte Maturation Captured in 3D Cerebral Cortical Spheroids Derived from Pluripotent Stem Cells. Neuron. 2017;95(4):779-90 e6.

78. Bhaduri A, Andrews MG, Mancia Leon W, Jung D, Shin D, Allen D, et al. Cell stress in cortical organoids impairs molecular subtype specification. Nature. 2020.

79. Amiri A, Coppola G, Scuderi S, Wu F, Roychowdhury T, Liu F, et al. Transcriptome and epigenome landscape of human cortical development modeled in organoids. Science. 2018;362:6420.

80. Camp JG, Badsha F, Florio M, Kanton S, Gerber T, Wilsch-Brauninger M, et al. Human cerebral organoids recapitulate gene expression programs of fetal neocortex development. Proc Natl Acad Sci U S A. 2015;112(51):15672-7.

81. Quadrato G, Nguyen T, Macosko EZ, Sherwood JL, Min Yang S, Berger DR, et al. Cell diversity and network dynamics in photosensitive human brain organoids. Nature. 2017:545(7652):48-53.

82. Kanton S, Boyle MJ, He Z, Santel M, Weigert A, Sanchís-Calleja F, et al. Organoid single-cell genomic atlas uncovers human-specific features of brain development. Nature. 2019;574(7778):418-22.

83. Pollen AA, Bhaduri A, Andrews MG, Nowakowski TJ, Meyerson OS, MostajoRadji MA, et al. Establishing cerebral organoids as models of human-specific brain evolution. Cell. 2019;176(4):743-56.e17.

84. Velasco S, Kedaigle AJ, Simmons SK, Nash A, Rocha M, Quadrato G, et al. Individual brain organoids reproducibly form cell diversity of the human cerebral cortex. Nature. 2019;1.

85. Birey F, Andersen J, Makinson CD, Islam S, Wei W, Huber N, et al. Assembly of functionally integrated human forebrain spheroids. Nature. 2017; 545(7652):54-9.

86. Yoon SJ, Elahi LS, Pasca AM, Marton RM, Gordon A, Revah O, et al. Reliability of human cortical organoid generation. Nat Methods. 2019;16(1):75-8.

87. Xiang Y, Tanaka Y, Patterson B, Kang YJ, Govindaiah G, Roselaar N, et al. Fusion of regionally specified hPSC-derived organoids models human brain development and interneuron migration. Cell Stem Cell. 2017;21(3):383-98 e7.

88. Bagley JA, Reumann D, Bian S, Levi-Strauss J, Knoblich JA. Fused cerebral organoids model interactions between brain regions. Nat Methods. 2017; 14(7):743-51.

89. Trevino AE, Sinnott-Armstrong N, Andersen J, Yoon SJ, Huber N, Pritchard $\mathrm{JK}$, et al. Chromatin accessibility dynamics in a model of human forebrain development. Science. 2020;367:6476.

90. Franchini LF, Pollard KS. Human evolution: the non-coding revolution. BMC Biol. 2017;15(1):89.

91. Engle SJ, Blaha L, Kleiman RJ. Best practices for translational disease modeling using human iPSC-derived neurons. Neuron. 2018;100(4):783-97.

92. Shelton JF, Geraghty EM, Tancredi DJ, Delwiche LD, Schmidt RJ, Ritz B, et al Neurodevelopmental disorders and prenatal residential proximity to agricultural pesticides: the CHARGE study. Environ Health Perspect. 2014; 122(10):1103-9.

93. Stein TP, Schluter MD, Steer RA, Guo L, Ming X. Bisphenol A Exposure in children with autism spectrum disorders. Autism Res. 2015;8(3):272-83.
94. Modabbernia A, Velthorst E, Reichenberg A. Environmental risk factors for autism: an evidence-based review of systematic reviews and meta-analyses. Mol Autism. 2017;8(1):13

95. Freitas BC, Mei A, Mendes APD, Beltrão-Braga PCB, Marchetto MC. Modeling Inflammation in autism spectrum disorders using stem cells. Front Pediatr. 2018;6:394.

96. Raciti M, Ong J, Weis L, Edoff K, Battagli C, Falk A, et al. Glucocorticoids alter neuronal differentiation of human neuroepithelial-like cells by inducing long-lasting changes in the reactive oxygen species balance. Neuropharmacology. 2016;107:422-31.

97. Gibbs RM, Lipnick S, Bateman JW, Chen L, Cousins HC, Hubbard EG, et al. Toward precision medicine for neurological and neuropsychiatric disorders. Cell Stem Cell. 2018;23(1):21-4.

98. Yang Y, Muzny DM, Reid JG, Bainbridge MN, Willis A, Ward PA, et al. Clinical whole-exome sequencing for the diagnosis of Mendelian disorders. N E J Med. 2013;369(16):1502-11.

99. Byron SA, Van Keuren-Jensen KR, Engelthaler DM, Carpten JD, Craig DW Translating RNA sequencing into clinical diagnostics: opportunities and challenges. Nat Rev Genet. 2016;17(5):257-71.

100. Cummings BB, Marshall JL, Tukiainen T, Lek M, Donkervoort S, Foley AR, et al. Improving genetic diagnosis in Mendelian disease with transcriptome sequencing. Sci Translat Med. 2017;9:386.

101. Lee $H$, Huang AY, Wang LK, Yoon AJ, Renteria G, Eskin A, et al. Diagnostic utility of transcriptome sequencing for rare Mendelian diseases. Genet Med. 2019.

102. Frésard L, Smail C, Ferraro NM, Teran NA, Li X, Smith KS, et al. Identification of rare-disease genes using blood transcriptome sequencing and large control cohorts. Nat Med. 2019;1.

103. Geschwind DH, Flint J. Genetics and genomics of psychiatric disease. Science. 2015:349(6255):1489-94.

104. Little D, Ketteler R, Gissen P, Devine MJ. Using stem cell-derived neurons in drug screening for neurological diseases. Neurobiol Aging. 2019;78:130-41.

105. Sherman SP, Bang AG. High-throughput screen for compounds that modulate neurite growth of human induced pluripotent stem cell-derived neurons. Dis Model Mech. 2018;11:2.

106. Gilbert J, Man H-Y. Fundamental elements in autism: from neurogenesis and neurite growth to synaptic plasticity. Front Cell Neurosci. 2017;11.

107. Kaufmann M, Schuffenhauer A, Fruh I, Klein J, Thiemeyer A, Rigo P, et al. High-throughput screening using iPSC-derived neuronal progenitors to identify compounds counteracting epigenetic gene silencing in fragile $X$ syndrome. J Biomol Screen. 2015;20(9):1101-11.

108. Darville H, Poulet A, Rodet-Amsellem F, Chatrousse L, Pernelle J, Boissart C, et al. Human pluripotent stem cell-derived cortical neurons for high throughput medication screening in autism: a proof of concept study in SHANK3 haploinsufficiency syndrome. EBio Med. 2016;9:293-305.

109. Mertens J, Wang QW, Kim Y, Yu DX, Pham S, Yang B, et al. Differential responses to lithium in hyperexcitable neurons from patients with bipolar disorder. Nature. 2015;527(7576):95-9.

110. Marchetto MC, Hrvoj-Mihic B, Kerman BE, Yu DX, Vadodaria KC, Linker SB, et al. Species-specific maturation profiles of human, chimpanzee and bonobo neural cells. eLife. 2019;8:e37527.

111. Otani T, Marchetto MC, Gage FH, Simons BD, Livesey FJ. 2D and 3D stem cell models of primate cortical development identify species-specific differences in progenitor behavior contributing to brain size. Cell Stem Cell. 2016;18(4):467-80.

112. DeRosa BA, El Hokayem J, Artimovich E, Garcia-Serje C, Phillips AW, Van Booven D, et al. Convergent pathways in idiopathic autism revealed by time course transcriptomic analysis of patient-derived neurons. Sci Rep. 2018;8(1):8423.

113. Griesi-Oliveira K, Suzuki AM, Alves AY, Mafra A, Yamamoto GL, Ezquina S, et al. Actin cytoskeleton dynamics in stem cells from autistic individuals. Sci Rep. 2018;8(1):11138.

114. Schafer ST, Paquola ACM, Stern S, Gosselin D, Ku M, Pena M, et al. Pathological priming causes developmental gene network heterochronicity in autistic subject-derived neurons. Nat Neurosci. 2019;22(2):243-55.

115. Liu X, Campanac E, Cheung HH, Ziats MN, Canterel-Thouennon L, Raygada $M$, et al. Idiopathic autism: cellular and molecular phenotypes in pluripotent stem cell-derived neurons. Mol Neurobiol. 2017;54(6):4507-23.

116. Russo FB, Freitas BC, Pignatari GC, Fernandes IR, Sebat J, Muotri AR, et al. Modeling the interplay between neurons and astrocytes in autism using human induced pluripotent stem cells. Biological Psychiatry. 2018:83(7):569-78. 
117. Adhya D, Swarup V, Nagy R, Shum C, Nowosiad P, Jozwik KM, et al. Atypical neurogenesis and excitatory-inhibitory progenitor generation in induced pluripotent stem cell (iPSC) from autistic individuals. bioRxiv. 2019;349415.

118. Moore D, Meays BM, Madduri LSV, Shahjin F, Chand S, Niu M, et al. Downregulation of an evolutionary young miR-1290 in an iPSC-derived neural stem cell model of autism spectrum disorder. Stem Cells Int. 2019; 2019:8710180

119. Wang M, Wei PC, Lim CK, Gallina IS, Marshall S, Marchetto MC, et al. Increased neural progenitor proliferation in a hiPSC model of autism induces replication stress-associated genome instability. Cell Stem Cell. 2020;26(2):221-33 e6.

120. Griesi-Oliveira K, Fogo MS, Pinto BGG, Alves AY, Suzuki AM, Morales AG, et al. Transcriptome of iPSC-derived neuronal cells reveals a module of coexpressed genes consistently associated with autism spectrum disorder. Mol Psychiatry. 2020.

121. Fink JJ, Robinson TM, Germain ND, Sirois CL, Bolduc KA, Ward AJ, et al. Disrupted neuronal maturation in Angelman syndrome-derived induced pluripotent stem cells. Nat Commun. 2017;8:15038.

122. Fink JJ, Schreiner JD, Bloom JE, Baker DS, Robinson TM, Lieberman $\mathrm{R}$, et al. Hyperexcitable phenotypes in iPSC-derived neurons from patients with 15q11-q13 duplication syndrome, a genetic form of autism. bioRxiv. 2018; 286336

123. Lin M, Lachman HM, Zheng D. Transcriptomics analysis of iPSC-derived neurons and modeling of neuropsychiatric disorders. Mol Cell Neurosci. 2016;73:32-42

124. Toyoshima M, Akamatsu W, Okada Y, Ohnishi T, Balan S, Hisano Y, et al. Analysis of induced pluripotent stem cells carrying 22q11.2 deletion. Transl Psychiatry. 2016;6(11):e934.

125. Deshpande A, Yadav S, Dao DQ, Wu ZY, Hokanson KC, Cahill MK, et al. Cellular phenotypes in human iPSC-derived neurons from a genetic mode of autism spectrum disorder. Cell Rep. 2017;21(10):2678-87.

126. Gillentine MA, Yin J, Bajic A, Zhang P, Cummock S, Kim JJ, et al. Functional consequences of CHRNA7 copy-number alterations in induced pluripotent stem cells and neural progenitor cells. Am J Hum Genet. 2017;101(6):874-87.

127. Yi F, Danko T, Botelho SC, Patzke C, Pak C, Wernig M, et al. Autismassociated SHANK3 haploinsufficiency causes Ih channelopathy in human neurons. Science. 2016;352(6286):aaf2669.

128. Kathuria A, Nowosiad P, Jagasia R, Aigner S, Taylor RD, Andreae LC, et al. Stem cell-derived neurons from autistic individuals with SHANK3 mutation show morphogenetic abnormalities during early development. Mol Psychiatry. 2018;23(3):735-46.

129. Gouder L, Vitrac A, Goubran-Botros H, Danckaert A, Tinevez JY, AndreLeroux $\mathrm{G}$, et al. Altered spinogenesis in iPSC-derived cortical neurons from patients with autism carrying de novo SHANK3 mutations. Sci Rep. 2019; 9(1):94.

130. Huang G, Chen S, Chen X, Zheng J, Xu Z, Doostparast Torshizi A, et al. Uncovering the functional link between SHANK3 deletions and deficiency in neurodevelopment using iPSC-derived human neurons. Front Neuroanat. 2019;13:23.

131. Wang P, Mokhtari R, Pedrosa E, Kirschenbaum M, Bayrak C, Zheng D, et al. CRISPR/Cas9-mediated heterozygous knockout of the autism gene CHD8 and characterization of its transcriptional networks in cerebral organoids derived from iPS cells. Mol Autism. 2017:8:11.

132. Sugathan A, Biagioli M, Golzio C, Erdin S, Blumenthal I, Manavalan P, et al. CHD8 regulates neurodevelopmental pathways associated with autism spectrum disorder in neural progenitors. PNAS. 2014;111(42):E4468-E77.

133. Pak C, Danko T, Zhang Y, Aoto J, Anderson G, Maxeiner S, et al. Human neuropsychiatric disease modeling using conditional deletion reveals synaptic transmission defects caused by heterozygous mutations in NRXN1. Cell Stem Cell. 2015;17(3):316-28.

134. Zeng L, Zhang P, Shi L, Yamamoto V, Lu W, Wang K. Functional impacts of NRXN1 knockdown on neurodevelopment in stem cell models. PLoS One. 2013;8:3.

135. Lam M, Moslem M, Bryois J, Pronk RJ, Uhlin E, Ellstrom ID, et al. Single cell analysis of autism patient with bi-allelic NRXN1-alpha deletion reveals skewed fate choice in neural progenitors and impaired neuronal functionality. Exp Cell Res. 2019;383(1):111469.

136. Avazzadeh S, McDonagh K, Reilly J, Wang Y, Boomkamp SD, Mclnerney V, et al. Increased $\mathrm{Ca}(2+)$ signaling in NRXN1alpha (+/-) neurons derived from ASD induced pluripotent stem cells. Mol Autism. 2019;10:52.
137. Flaherty E, Zhu S, Barretto N, Cheng E, Deans PJM, Fernando MB, et al. Neuronal impact of patient-specific aberrant NRXN1alpha splicing. Nat Genet. 2019;51(12):1679-90.

138. Marro SG, Chanda S, Yang N, Janas JA, Valperga G, Trotter J, et al. Neuroligin-4 regulates excitatory synaptic transmission in human neurons. Neuron. 2019:103(4):617-26 e6.

139. Frega M, Linda K, Keller JM, Gumus-Akay G, Mossink B, van Rhijn JR, et al. Neuronal network dysfunction in a model for Kleefstra syndrome mediated by enhanced NMDAR signaling. Nat Commun. 2019;10(1):4928.

140. Ross PJ, Zhang WB, Mok RSF, Zaslavsky K, Deneault E, D'Abate L, et al. Synaptic dysfunction in human neurons with autism-associated deletions in PTCHD1-AS. Biol Psychiatry. 2020;87(2):139-49.

141. Sun AX, Yuan Q, Fukuda M, Yu W, Yan H, Lim GGY, et al. Potassium channel dysfunction in human neuronal models of Angelman syndrome. Science. 2019:366(6472):1486-92.

142. Paşca SP, Portmann T, Voineagu I, Yazawa M, Shcheglovitov A, Paşca AM, et al. Using iPSC-derived neurons to uncover cellular phenotypes associated with Timothy syndrome. Nat Med. 2011;17(12):1657-62.

143. Lewis EMA, Meganathan K, Baldridge D, Gontarz P, Zhang B, Bonni A, et al. Cellular and molecular characterization of multiplex autism in human induced pluripotent stem cell-derived neurons. Mol Autism. 2019;10:51.

144. Lin M, Pedrosa E, Hrabovsky A, Chen J, Puliafito BR, Gilbert SR, et al. Integrative transcriptome network analysis of iPSC-derived neurons from schizophrenia and schizoaffective disorder patients with 22q11.2 deletion. BMC Syst Biol. 2016;10(1):105.

145. Deneault E, Faheem M, White SH, Rodrigues DC, Sun S, Wei W, et al. CNTN5(-)(/+)or EHMT2(-)(/+)human iPSC-derived neurons from individuals with autism develop hyperactive neuronal networks. Elife. 2019;8.

146. Zaslavsky K, Zhang WB, McCready FP, Rodrigues DC, Deneault E, Loo C, et al. SHANK2 mutations associated with autism spectrum disorder cause hyperconnectivity of human neurons. Nat Neurosci. 2019;22(4):556-64.

147. Deneault E, White SH, Rodrigues DC, Ross PJ, Faheem M, Zaslavsky K, et al. Complete disruption of autism-susceptibility genes by gene editing predominantly reduces functional connectivity of isogenic human neurons. Stem Cell Rep. 2018;11(5):1211-25.

148. Abu Diab M, Eiges R. The contribution of pluripotent stem cell (PSC)-based models to the study of fragile $X$ syndrome (FXS). Brain Sci. 2019;9(2).

149. Vershkov D, Ben-Hur T, Benvenisty N. Chapter 6 - Modeling fragile $X$ syndrome using human pluripotent stem cells. In: Willemsen R, Kooy RF, editors. Fragile X Syndrome: Academic Press; 2017. p. 103-21.

150. Telias M. Molecular Mechanisms of synaptic dysregulation in fragile $X$ syndrome and autism spectrum disorders. Front Mol Neurosci. 2019;12:51.

151. Lee KM, Hawi ZH, Parkington HC, Parish CL, Kumar PV, Polo JM, et al. The application of human pluripotent stem cells to model the neuronal and glial components of neurodevelopmental disorders. Mol Psychiatry. 2020; 25(2):368-78.

152. Shen $X$, Yeung HT, Lai KO. Application of human-induced pluripotent stem cells (hiPSCs) to study synaptopathy of neurodevelopmental disorders. Dev Neurobiol. 2019;79(1):20-35.

153. Ben-Reuven L, Reiner O. Modeling the autistic cell: iPSCs recapitulate developmental principles of syndromic and nonsyndromic ASD. Dev Growth Different. 2016;58(5):481-91.

154. Blair JD, Bateup HS. New frontiers in modeling tuberous sclerosis with human stem cell-derived neurons and brain organoids. Dev Dyn. 2020; 249(1):46-55.

155. Pramparo T, Lombardo MV, Campbell K, Barnes CC, Marinero S, Solso S, et al. Cell cycle networks link gene expression dysregulation, mutation, and brain maldevelopment in autistic toddlers. Mol Syst Biol. 2015;11(12).

156. Courchesne E, Campbell K, Solso S. Brain growth across the life span in autism: age-specific changes in anatomical pathology. Brain Res. 2011;1380: 138-45.

157. Sacco R, Gabriele S, Persico AM. Head circumference and brain size in autism spectrum disorder: a systematic review and meta-analysis. Psychiatry Res. 2015;234(2):239-51.

158. Dong D, Zielke HR, Yeh D, Yang P. Cellular stress and apoptosis contribute to the pathogenesis of autism spectrum disorder. Autism Res. 2018;11(7): 1076-90.

159. van Rooij D, Anagnostou E, Arango C, Auzias G, Behrmann M, Busatto GF, et al. Cortical and subcortical brain morphometry differences between patients with autism spectrum disorder and healthy individuals across the lifespan: results from the ENIGMA ASD Working Group. AJP. 2017;175(4):359-69. 
160. Button KS, Ioannidis JPA, Mokrysz C, Nosek BA, Flint J, Robinson ESJ, et al. Power failure: why small sample size undermines the reliability of neuroscience. Nat Rev Neurosci. 2013;14(5):365-76.

161. Parikshak NN, Swarup V, Belgard TG, Irimia M, Ramaswami G, Gandal MJ, et al. Genome-wide changes in IncRNA, splicing, and regional gene expression patterns in autism. Nature. 2016.

162. Velmeshev D, Schirmer L, Jung D, Haeussler M, Perez Y, Mayer S, et al. Single-cell genomics identifies cell type-specific molecular changes in autism. Science. 2019;364(6441):685-9.

163. Voineagu I, Wang X, Johnston P, Lowe JK, Tian Y, Horvath S, et al. Transcriptomic analysis of autistic brain reveals convergent molecular pathology. Nature. 2011;474(7351):380-4.

164. Abraham JR, Szoko N, Barnard J, Rubin RA, Schlatzer D, Lundberg K, et al. Proteomic investigations of autism brain identify known and novel pathogenetic processes. Sci Rep. 2019;9(1):13118.

165. Gandal MJ, Haney JR, Parikshak NN, Leppa V, Ramaswami G, Hartl C, et al. Shared molecular neuropathology across major psychiatric disorders parallels polygenic overlap. Science. 2018:359(6376):693-7.

166. Gandal MJ, Zhang P, Hadjimichael E, Walker RL, Chen C, Liu S, et al. Transcriptome-wide isoform-level dysregulation in ASD, schizophrenia, and bipolar disorder. Science. 2018;362(6420).

167. Liu X, Campanac E, Cheung HH, Ziats MN, Canterel-Thouennon L, Raygada $M$, et al. Idiopathic autism: cellular and molecular phenotypes in pluripotent stem cell-derived neurons. Mol Neurobiol. 2016.

168. Sohal VS, Rubenstein JLR. Excitation-inhibition balance as a framework for investigating mechanisms in neuropsychiatric disorders. Mol Psychiatry. 2019;24(9):1248-57.

169. Watanabe M, Buth JE, Vishlaghi N, de la Torre-Ubieta L, Taxidis J, Khakh BS, et al. Self-organized cerebral organoids with human-specific features predic effective drugs to combat Zika virus infection. Cell Rep. 2017;21(2):517-32.

170. Du F, Yu Q, Chen A, Chen D, Yan SS. Astrocytes attenuate mitochondrial dysfunctions in human dopaminergic neurons derived from iPSC. Stem Cell Rep. 2018;10(2):366-74.

171. Tripathi P, Rodriguez-Muela N, Klim JR, de Boer AS, Agrawal S, Sandoe J, et al. Reactive astrocytes promote ALS-like degeneration and intracellular protein aggregation in human motor neurons by disrupting autophagy through TGF- $\beta 1$. Stem Cell Rep. 2017;9(2):667-80.

172. Donovan APA, Basson MA. The neuroanatomy of autism - a developmental perspective. J Anatomy. 2017;230(1):4-15.

173. Muguruma K, Nishiyama A, Kawakami H, Hashimoto K, Sasai Y. Selforganization of polarized cerebellar tissue in 3D culture of human pluripotent stem cells. Cell Rep. 2015;10(4):537-50.

174. Jo J, Xiao Y, Sun Alfred X, Cukuroglu E, Tran H-D, Göke J, et al. Midbrain-like organoids from human pluripotent stem cells contain functional dopaminergic and neuromelanin-producing neurons. Cell Stem Cell. 2016; 19(2):248-57.

175. Nicholas CR, Chen J, Tang Y, Southwell DG, Chalmers N, Vogt D, et al. Functional maturation of hPSC-derived forebrain interneurons requires an extended timeline and mimics human neural development. Cell Stem Cell. 2013;12(5):573-86.

176. Merkle FT, Maroof A, Wataya T, Sasai Y, Studer L, Eggan K, et al. Generation of neuropeptidergic hypothalamic neurons from human pluripotent stem cells. Development. 2015;142(4):633-43.

177. Giandomenico SL, Mierau SB, Gibbons GM, Wenger LMD, Masullo L, Sit T, et al. Cerebral organoids at the air-liquid interface generate diverse nerve tracts with functional output. Nat Neurosci. 2019;22(4):669.

178. Stogsdill JA, Eroglu C. The interplay between neurons and glia in synapse development and plasticity. Curr Opin Neurobiol. 2017;42:1-8.

179. Reemst K, Noctor SC, Lucassen PJ, Hol EM. The indispensable roles of microglia and astrocytes during brain development. Front Hum Neurosci. 2016;10.

180. Germain PL, Testa G. Taming Human genetic variability: transcriptomic meta-analysis guides the experimental design and interpretation of iPSCbased disease modeling. Stem Cell Rep. 2017;8(6):1784-96.

181. Lomax GP, DeWitt ND, Millan MT, Feigal EG. How California Institute for Regenerative Medicine research programs support science and regulatory policy. Stem Cells Transl Med. 2014;3(6):673-4

182. De Sousa PA, Steeg R, Wachter E, Bruce K, King J, Hoeve M, et al. Rapid establishment of the European Bank for induced Pluripotent Stem Cells (EBiSC) - the Hot Start experience. Stem Cell Res. 2017;20:105-14.
183. Kim J-H, Kurtz A, Yuan B-Z, Zeng F, Lomax G, Loring JF, et al. Report of the International Stem Cell Banking Initiative Workshop Activity: current hurdles and progress in seed-stock banking of human pluripotent stem cells. Stem Cells Transl Med. 2017:6(11):1956-62.

184. Sridharan B, Hubbs C, Llamosas N, Kilinc M, Singhera FU, Willems E, et al. A simple procedure for creating scalable phenotypic screening assays in human neurons. Sci Rep. 2019;9(1):9000

185. Marton RM, Miura Y, Sloan SA, Li Q, Revah O, Levy RJ, et al. Differentiation and maturation of oligodendrocytes in human three-dimensional neural cultures. Nat Neurosci. 2019.

186. Madhavan M, Nevin ZS, Shick HE, Garrison E, Clarkson-Paredes C, Karl M, et al. Induction of myelinating oligodendrocytes in human cortical spheroids. Nat Methods. 2018;15(9):700-6.

187. McQuade A, Coburn M, Tu CH, Hasselmann J, Davtyan H, Blurton-Jones M. Development and validation of a simplified method to generate human microglia from pluripotent stem cells. Mol Neurodegener. 2018;13(1):67.

188. Abud EM, Ramirez RN, Martinez ES, Healy LM, Nguyen CHH, Newman SA, et al. iPSC-derived human microglia-like cells to study neurological diseases. Neuron. 2017;94(2):278-93 e9.

189. Muffat J, Li Y, Yuan B, Mitalipova M, Omer A, Corcoran S, et al. Efficient derivation of microglia-like cells from human pluripotent stem cells. Nat Med. 2016:22(11):1358-67.

190. Oksdath M, Perrin SL, Bardy C, Hilder EF, DeForest CA, Arrua RD, et al. Review: Synthetic scaffolds to control the biochemical, mechanical, and geometrical environment of stem cell-derived brain organoids. APL Bioeng. 2018;2(4):041501.

191. Zuppinger C. 3D cardiac cell culture: a critical review of current technologies and applications. Front Cardiovasc Med. 2019;6:87.

192. Song JJ, Guyette JP, Gilpin SE, Gonzalez G, Vacanti JP, Ott HC. Regeneration and experimental orthotopic transplantation of a bioengineered kidney. Nat Med. 2013;19(5):646-51.

193. Qi Y, Zhang X-J, Renier N, Wu Z, Atkin T, Sun Z, et al. Combined smallmolecule inhibition accelerates the derivation of functional cortical neurons from human pluripotent stem cells. Nat Biotechnol. 2017;35(2):154-63.

194. Canfield SG, Stebbins MJ, Faubion MG, Gastfriend BD, Palecek SP, Shusta EV. An isogenic neurovascular unit model comprised of human induced pluripotent stem cell-derived brain microvascular endothelial cells, pericytes, astrocytes, and neurons. Fluids Barriers CNS. 2019;16(1):25.

195. Mansour AA, Goncalves JT, Bloyd CW, Li H, Fernandes S, Quang D, et al. An in vivo model of functional and vascularized human brain organoids. Nat Biotechnol. 2018;36(5):432-41.

196. Daviaud N, Friedel RH, Zou H. Vascularization and Engraftment of transplanted human cerebral organoids in mouse cortex. eNeuro. 2018;5(6).

\section{Publisher's Note}

Springer Nature remains neutral with regard to jurisdictional claims in published maps and institutional affiliations.

Ready to submit your research? Choose BMC and benefit from:

- fast, convenient online submission

- thorough peer review by experienced researchers in your field

- rapid publication on acceptance

- support for research data, including large and complex data types

- gold Open Access which fosters wider collaboration and increased citations

- maximum visibility for your research: over $100 \mathrm{M}$ website views per year

At $\mathrm{BMC}$, research is always in progress.

Learn more biomedcentral.com/submissions 